\title{
KARYOTYPIC STUDIES OF FOUR PHYSALIS SPECIES FROM NIGERIA
}

\author{
S. O. Azeez and J. O. FAluYi \\ Department of Botany, Faculty of Science, Obafemi Awolowo University, Ile-Ife, Nigeria \\ E-mails: sekinatokiki@gmail.com; azeezs@oauife.edu.ng; jfaluyi@gmail.com
}

(Received 30 July, 2017; Accepted 4 March, 2018)

\begin{abstract}
Mitotic chromosomes from root tips of four Nigerian Physalis species were investigated using standard cytogenetic methods. $P$. angulata has chromosome number of $2 n=48$ with karyotypic formula of $2 \mathrm{M}+5 \mathrm{~m}+16 \mathrm{sm}+1 \mathrm{st}$, while $P$. micrantha, $P$. peruviana and $P$. pubescens showed the same chromosome number of $2 \mathrm{n}=24$ with karyotypic formulae of $1 \mathrm{M}+$ $1 \mathrm{~m}+9 \mathrm{sm}+1 \mathrm{st}, 4 \mathrm{M}+6 \mathrm{~m}+1 \mathrm{sm}+1 \mathrm{st}$ and $1 \mathrm{M}+1 \mathrm{~m}+2 \mathrm{sm}+8 \mathrm{st}$, respectively. The karyotypes show that $P$. angulata is more advanced when compared to the other three diploids studied.
\end{abstract}

Key words: chromosome, diploid, karyotype, Physalis, tetraploid

\section{INTRODUCTION}

The genus Physalis (Solanaceae), which consists of about 100 species (ElSheikha et al. 2009, Sultana et al. 2008) was divided into nine sections: Pubescentes, Angulatae, Philadelphicae, Carpenterianae, Lanceolatae, Heterophyllae, Viscosae, Crassifoliae and Megista (Menzel 1951). Physalis is found both in temperate and tropical America and a few species were discovered in East Asia, India, Australia, Europe and tropical Africa (Menzel 1951). The generic borders are identified by the pendant flowers and inflated fruiting calyx, which contains the berry (Sullivan 1984). Four species were identified in West Africa, as well as Nigeria (Hutchinson and Dalziel 1963, Olatunji 1985). They are $P$. angulata L., P. peruviana L., P. micrantha Link and P. pubescens L.

The basic number for this genus is $\mathrm{x}=12$ with the exception of $P$. lobuta which has $x=11$. The chromosome numbers, $2 n=24$ and $2 n=48$ have been reported for $P$. angulata and $P$. peruviana, while $2 \mathrm{n}=24$ was recorded for $P$. micrantha and P. pubescens (Burkill 2000, Husaini and Iwo 1990, Martinez 1998, Menzel 1951, Olorode et al. 2013, Rodríguez and Bueno 2006, Wahua and Sam 2013). However, there is no record of known work on karyotypic studies on the Physalis species in Nigeria. This study investigated mitotic chromosomes of these four Physalis species in order to elucidate the karyotypic variation among the species with respect to their karyotype. 


\section{MATERIALS AND METHODS}

The four Nigerian Physalis species studied were collected from different locations in Nigeria. P. peruviana, $P$. angulata and $P$. pubescens were collected from Ile-Ife $\left(7^{\circ} 35^{\prime} 25.84^{\prime \prime} \mathrm{N}, 4^{\circ} 44^{\prime} 00.81^{\prime \prime} \mathrm{E}\right)$ and P. micrantha was collected from Ogbomosho ( $8^{\circ} 08^{\prime} 00.00^{\prime \prime} \mathrm{N}, 4^{\circ} 15^{\prime} 00.00^{\prime \prime}$ E). Voucher specimens of each species were deposited at IFE herbarium, Obafemi Awolowo University, IleIfe, Nigeria.

Mitotic chromosomes were studied from the harvested root tips of seedlings using squash method according to Lasebikan and Olorode (1972). The root tips were also harvested between $9.00 \mathrm{am}$ and $12.00 \mathrm{pm}$. The harvested root tips were pre-treated in $0.002 \mathrm{M}$ 8-hydroquinoline for 2 hours and then fixed in 1:3 acetic acid: ethanol. The root tips for examination were hydrolysed in $18 \% \mathrm{HCl}$ for 30 minutes, squashed and stained in FLP-orcein. The photomicrographs of good mitotic chromosome spreads were taken with an Amscope MT microscope Camera version 3.0.0.1 attached to a light microscope.

The chromosomes were paired by physical analysis of chromosomes based on arm length ratio as described by Torres and Liogier (1970). The arm ratio was calculated from the ratio of long arm length to short arm length, while the centromeric index was determined from the ratio of short arm to addition of short arm and long arm. The chromosome types, as well as the centromeric position were determined according to the method of Jiang et al. (2011). The chromosome complements were further classified according to Stebbins (1971). The karyotype asymmetry was determined based on variation in chromosome length and proportion of arm ratio (i.e. centromere position of chromosome pairs) greater than 2 .

\section{RESULTS}

Physalis angulata chromosomes $(\mathrm{n}=24)$ showed that the chromosome pairs were mostly submetacentric with 16 pairs being submetacentric chromosomes out of 24 pairs (Table 1). The mean chromosome length of $P$. angulata ranged between 0.99 and $1.71 \mu \mathrm{m}$. The average centromeric index was $34.07 \%$. The ratio of the longest to shortest chromosome was 1.73 , while the proportion of chromosomes with arm ratio $>2$ was 0.38 , thereby placing the karyotype of $P$. angulata in 2A Stebbins category. The karyotypic formula for $P$. angulata was $2 \mathrm{M}+5 \mathrm{~m}+16 \mathrm{sm}+1$ st.

The centromeric position of the chromosome pairs of $P$. pubescens was mostly in the subtelocentric region and terminal point. The mean chromosome length ranged between 1.89 and $1.26 \mu \mathrm{m}$. All the chromosome pairs were either medium, long or medium short chromosomes (Table 1). The average centromeric index was $43.18 \%$. The longest : shortest chromosome length 
Table 1

Summary of karyomorphological features of the four Physalis species studied

\begin{tabular}{lcccc}
\hline Species & $\begin{array}{c}\text { Mean total } \\
\text { chromosome } \\
\text { length }\end{array}$ & $\begin{array}{c}\text { Centro- } \\
\text { meric index } \\
(\%)\end{array}$ & Karyotypic formula & $\begin{array}{c}\text { Stebbin's } \\
\text { category }\end{array}$ \\
\hline P. angulata $(\mathrm{n}=24)$ & $31.81 \pm 0.02$ & 34.07 & $2 \mathrm{M}+5 \mathrm{~m}+16 \mathrm{sm}+1 \mathrm{st}$ & $2 \mathrm{~A}$ \\
$P$. pubescens $(\mathrm{n}=12)$ & $18.68 \pm 0.09$ & 43.18 & $1 \mathrm{M}+1 \mathrm{~m}+2 \mathrm{sm}+8 \mathrm{st}$ & $3 \mathrm{~A}$ \\
$P$. micrantha $(\mathrm{n}=12)$ & $24.98 \pm 0.14$ & 35.21 & $1 \mathrm{M}+1 \mathrm{~m}+9 \mathrm{sm}+1 \mathrm{st}$ & $2 \mathrm{~A}$ \\
P.peruviana $(\mathrm{n}=12)$ & $17.43 \pm 0.17$ & 42.77 & $1 \mathrm{M}+1 \mathrm{~m}+9 \mathrm{sm}+1 \mathrm{st}$ & $2 \mathrm{~B}$ \\
\hline
\end{tabular}

ratio was 1.5. The proportion of chromosome length arm ratio $>2$ was 0.83 . This made the karyotype to be in the 3A Stebbins category. The karyotypic formula was $1 \mathrm{M}+1 \mathrm{~m}+2 \mathrm{sm}+8$ st.

In $P$. micrantha $(\mathrm{n}=12)$, the mean chromosome length ranged between $1.53 \mu \mathrm{m}$ and $2.52 \mu \mathrm{m}$. The chromosome pairs were mostly submetacentric and the chromosome type fell between medium, short and medium, long chromosomes, except chromosome 12 which was short (Table 1). The mean centromeric index was $35.21 \%$. The longest/shortest chromosome ratio was 1.65 . The chromosome pair proportion $>2$ was 0.5 . This made the karyotype to be in $2 \mathrm{~A}$ Stebbins category. The karyotypic formula of $P$. micrantha chromosome pairs was $1 \mathrm{M}+1 \mathrm{~m}+9 \mathrm{sm}+1 \mathrm{st}$.

The chromosome length in P. peruviana was between 0.90 and $1.98 \mu \mathrm{m}$. The centromeric position in these chromosome pairs were mostly in the median region and at the median position (Table 1). About $50 \%$ of the chromosome pairs were medium, long chromosomes. The mean centromeric index was $42.77 \%$. The proportion of chromosome arm ratio greater than 2 was 0.08 . The longest : shortest chromosome length ratio was 2.2. This placed the karyotype in the 2B Stebbins category. The karyotypic formula was $4 M+6 m+1 s m+1$ st.

\section{DISCUSSIONS AND CONCLUSION}

The average centromeric index of the chromosome pairs of the four Physalis species studied was between $34.07-43.18 \%$. The predominance of submetacentric and metacentric chromosomes observed in $P$. angulata is in agreement with the report of Menzel (1951). The centromeric index calculated for $P$. angulata in this study was $34.07 \%$, while Menzel (1951) reported between 34 and $38 \%$ for the section Angulatae, where P. angulata belongs to. Physalis pubescens and $P$. lagascae (which was reported as synonymy of $P$. micrantha by Raju et al. 2007) belong to the section Pubescentes, which has the centromeric index of $27-29 \%$. The chromosome complements were mainly subterminal as 
observed by Menzel (1951). However, only one chromosome pair was found to have its centromere at the subterminal region in $P$. micrantha as compared to 8 pairs in P. pubescens.

Physalis peruviana belongs to the section Heterophyllae. A centromeric index of 37\% was reported for the section (Menzel 1951). In this study, the centromeric index calculated for $P$. peruviana was $42.77 \%$. Ten chromosome pairs had their centromeres at median points and median regions. The other 2 pairs were submetacentric and subterminal chromosomes. In Menzel (1951) reports (with $n=24$ ), 16 pairs were metacentric and submetacentric chromosomes, while 8 pairs were subterminal chromosomes.

Out of the four Physalis species studied, only P. angulata is tetraploid. El-Nahas et al. (2000) stated that the presence of polyploidy in a certain taxon is an evidence of advancement. It is therefore hypothesised that $P$. angulata is the most advanced among the four Physalis species studied. The advancement of $P$. angulata over the other three species can explain its wider latitudinal range of distribution, as well as its large population reported by Olorode et al. (2013) as a result of its larger genome when compared to the rest. In ancient and primordial plants, symmetric karyotype was found to be predominant, while the asymmetric karyotype was mostly seen in the recent and specialised plants (Jiang et al. 2011). Therefore, asymmetric karyotypes are more advanced compared to symmetrical ones (Malik and Srivastava 2009). Symmetric karyotypes were reported by Laura et al. (2010) for Lycium species, which were mostly metacentric chromosomes with slight differences in size. This work suggested that $P$. pubescens is the most recent of the three diploid species followed by $P$. micrantha, while $P$. peruviana is the most primitive as evident by the presence of the highest number of metacentric chromosomes. This submission is in line with the report of Menzel (1951), who stated that section Pubescentes and Angulatae are more advanced than Heterophyllae.

It can therefore be concluded that $P$. angulata is the most advanced among the species studied, while $P$. peruviana is the most primitive.

\section{REFERENCES}

Burkill, H. M. (2000): The useful plants of west tropical Africa. Vol. 5, Ed. 2, Families S-Z. Cryptogams, Addenda. - Royal Botanic Gardens, Kew, Richmond, UK, 686 pp.

El-Nahas, A. I., Khalifa, S. F and Abuo-El-Enain, M. M. (2000): Karyological studies on the Solanaceae. - Pakistan J. Biol. Sci. 3(5): 717-720. https://doi.org/10.3923/pjbs.2000.717.720

El-Sheikha, A. F., Ribeyre, F., Larroque, M., Reynes, M. and Montet, D. (2009): Quality of Physalis (Physalis pubescens L.) juice packaged in glass bottles and flexible laminated packs during storage at $5^{\circ} \mathrm{C}$. - African J. Food, Agric. Nutr. Developm. 9(6): 13891405. https://doi.org/10.4314/ajfand.v9i6.46263 
Husaini, S. W. H. and Iwo, G. A. (1990): Cytomorphological studies in some weedy species of the family Solanaceae from Jos Plateau, Nigeria. - Feddes Repert. 101(1-2): 41-47. https://doi.org/10.1002/fedr.4911010103

Hutchinson, J. and Dalziel, J. M. (1963): Flora of west tropical Africa. Vol. 2. - Crown Agents for Oversea Governments and Administrations, Millbank London, 329 pp.

Jiang, X.-H., Zhu, Y.-H., Xuan, M. L. and She, C.-W. (2011): Karyotype analysis of three Solanum plants using combined PI-DAPI staining and double fluorescence in situ hybridization with 45S and 5S rDNA probes. - African J. Biotechnol. 10(82): 18948-18957. https://doi.org/10.5897/ajb09.1874

Lasebikan, A. B. and Olorode, O. (1972): Morphological variation and cytological aberrations in the natural population of Zonocerus variegatus L. (Orthoptera: Pyrgomorphidae). - Bull. Entomol. Soc. Nigeria 3: 127-133.

Laura, S., Las Peñas, M. L., Bernardello, G., Levin, R. A. and Miller, J. S. (2010): Karyotypes and fluorescent chromosome banding patterns in Southern African Lycium (Solanaceae). - Caryologia 63(1): 50-61. https://doi.org/10.1080/00087114.2010.10589708

Malik, A. and Srivastava, A. K. (2009): Karyotypic analysis of different populations of Carthamus tinctorius Linnaeus (Asteraceae). - Comp. Cytogen. 3(1): 51-55. https://doi .org/10.3897/compcytogen.v3i1.8

Martinez, M. (1998): Revision of Physalis Section Epeteiorhiza (Solanaceae). - Anal. Inst. Biol., UNAM, Ser. Bot. 69(2): 71-117.

Menzel, M. Y. (1951): The cytotaxonomy and genetics of Physalis. - Proceeds Amer. Phil. Soc. 95(2): 132-183.

Olatunji, O. A. (1985): The taxonomy of Physalis Linn. (Solanaceae) in Nigeria. - Nigerian J. Sci. 19(1-2): 20-25.

Olorode, O., Olayanju, S. and Garba, A. (2013): Physalis (Solanaceae) in Nigeria. - Ife J. Sci. 15(1): 101-109.

Raju, V. S., Reddy, C. S. and Rajarao, K. G. (2007): The myth of "minima" and "maxima", the species of Physalis in Indian subcontinent. - Acta Phytotax. Sinica 45(2): 239-245.

Rodríguez, N. C. and Bueno, M. L. (2006): Study of the cytogenetic diversity of Physalis peruviana L. (Solanaceae). - Acta Biol. Colomb. 11(2): 75-85.

Stebbins G. L. (1971): Chromosomal evolution in higher plants. - Edward Arnold, London.

Sullivan, J. R. (1984): Pollination biology of Physalis viscosa var. cinerascens (Solanaceae). - Amer. J. Bot. 71: 815-820. https://doi.org/10.2307/2443472

Sultana, N., Hassan, M. A., Begun, M. and Sultana, M. (2008): Physalis angulata L. (Solanaceae) - a new angiospermic record for Bangladesh. - Bangladesh J. Bot. 37(2): 195198. https://doi.org/10.3329/bjb.v37i2.1731

Torres, A. M. and Liogier, A. H. (1970): Chromosome numbers of Dominican Compositae. - Brittonia 22: 240-245. https://doi.org/10.2307/2805906

Wahua, C. and Sam, S. M. (2013): Comparative chemotaxonomic investigations on Physalis angulata Linn. and Physalis micrantha Linn. (Solanaceae). - Asian J. Appl. Sci. 1(5): 220-228. 
